\title{
El hombre tras los hechos: Naturaleza humana y política en la historiografía clásica, de Antonio Hermosa Andújar (2019), Athenaica Ediciones Universitarias, 246 p.
}

DOI: 10.17230/co-herencia.17.32.11

\section{Vicente Ordóñez \\ vordonez@uji.es}

¿Qué somos? Con esta pregunta se abre el ensayo El hombre tras los hechos, interrogándose Antonio Hermosa a sí mismo e interpelando directamente al lector, a quien alienta a reflexionar sobre las bases ético-políticas desde las que se organiza la convivencia o la justicia, desvinculando la cuestión de cualquier interpretación identitaria porque lo que está en juego es descubrir la estructura ontoantropológica del sapiens a partir de algunos documentos decisivos surgidos de la tradición occidental.

¿Qué somos, pues? La pregunta ha sido planteada. Explorar la oquedad que la pregunta abre es pensar con su autor las posibilidades perennes de la respuesta, una respuesta que pasa por subrayar no tanto las diferencias, sino aquello que tienen en común desde siempre los sujetos de una colectividad en cuanto seres sociales. Como indica en el prólogo, Antonio Hermosa intenta "descubrir qué tipo de individuo hay detrás de los hechos que se narran, así como elucidar la naturaleza de las ideas éticas y políticas en las que aquellos se enmarcan y adquieren sentido" (2019, p. 18). Para ello recurre, en la primera parte del ensayo, al relato de los poetas Hesíodo y Homero, en quienes halla una explicación del acto fundacional de la moralidad, una narración del paso de una concepción de la justicia subjetiva y, por tanto, arbitraria, a otra más objetiva e imparcial y, además, una exposición de los rasgos ontológicos que definen al ser humano -rasgos determinados por la acción técnica con la que se vence el obstáculo, la resistencia de lo que inicialmente se presenta como inflexible o absolutamente infranqueable-.

En la segunda parte, mucho más extensa y ambiciosa, Hermosa se vale del testimonio de los historiadores Tucídides, Salustio, Tito Livio y Tácito para dar cuenta, entre otros asuntos, de cómo 
la política y la ética configuran a lo largo del tiempo un nuevo ser humano, cuál es la relación entre la democracia y el hombre o cómo la naturaleza humana asegura la repetición de los episodios violentos que jalonan su historia y, asimismo, apunta en la dirección de la inevitable reproducción de la barbarie.

La primera idea-fuerza que Antonio Hermosa aborda es la del mal y el problema de la justicia. En este contexto, la Teogonía es el documento que muestra -con una claridad más transparente, si cabe, que el vidrio o el cuarzo, que las láminas de metacrilato acrílico y las hojas de plexiglás- cómo la acción violenta que altera el statu quo y siembra la discordia se contrarresta con unas fuerzas del bien que restauran tanto el equilibrio perdido como el orden alterado; por ello, escribe Hermosa:

Se requiere [...] refundar el orden conocido hasta ahora al objeto o de poner coto al peligro intuido en lo desconocido o, al menos, de reducir cuanto sea posible su incidencia. Es así cómo, casi en sordina y no sin contradicción, el mundo de fuerzas naturales se ha humanizado adoptando la forma de un mundo político, y cómo ahí la Justicia, en pleno mundo divino, anuncia su necesidad (2019, p. 26).

Pero hay más, porque ese nuevo orden trascendental anuncia la ruptura inevitable entre dioses y hombres que quedan, de ese modo, desamparados y deben esforzarse, trabajar, para construirse su propio mundo. Y al respecto téngase en consideración que la adusta moral que el poema hesiódico despliega es el telón de fondo sobre el que se va a establecer una sucesión lineal de los acontecimientos y, por tanto, una ideación metafísica del tiempo que prepara el surgimiento de las ciencias hipotético-deductivas como, de algún modo, lo prefigura el mito de Prometeo, la más acabada alegoría sobre el ser humano que nos ha legado la Antigüedad. Antonio Hermosa cifra en seis los rasgos de la condición humana que el mito pone de relieve: en la medida en que las acciones del hombre tienen consecuencias incontroladas e incontrolables, el primer rasgo se cifra en, precisamente, su capacidad técnica (el hombre como aprendiz de brujo); el segundo, es el del ser humano como chivo expiatorio, el pharmakós estudiado por Vernant y Vidal-Naquet; el tercero, la constatación de que el mal es interminable; el cuarto, su adaptabilidad plástica; el quinto, su ambigüedad moral; y, por último, 
el carácter social del sapiens, pues solo colectivamente, y teniendo al otro por igual, es posible que la justicia haga posible la aparición de ese valor tan preciado por el hombre a la par que intangible: la libertad (2019, p. 50).

En Homero, Antonio Hermosa analiza cómo la justicia se emancipa tanto de la venganza como del arbitrio: una justicia articulada desde estos dos polos negativos acaba con toda forma de civilización, de suerte que eliminar ambas, arbitrariedad y venganza, se convierte en el requisito sine qua non para terminar con toda forma de barbarie:

Lo que de ahí brota, en fin, es el principio del fin de la edad de oro de la subjetivación de la justicia y el inicio de su sustitución por una nueva forma más objetiva e imparcial, desvinculada del afectado y enraizada en una serie de creencias y prácticas sociales que con el tiempo darán lugar a su institucionalización, y con ella, a una legitimación a escala cada vez más general (2019, p. 75).

El héroe cede progresivamente al empuje de la normatividad, al tiempo que la legalidad se erige en contrapolo de la injusticia: el mundo de la ley, organizado en torno a ideas, costumbres y creencias que estructuran y correlacionan determinados fenómenos sociales, constituye el horizonte jurídico que ni reyes ni sacerdotes pueden sobrepasar.

Los cuatro primeros capítulos de la segunda parte del ensayo tienen a Tucídides como protagonista. Los temas aquí se suceden vertiginosamente y el lector debe estar atento a los muchos matices que el profesor Hermosa subraya, principalmente porque en algunos pasajes de La Guerra del Peloponeso se expone, condensada, la antropología de la democracia. ¿Cómo influye sobre los ciudadanos convivir en democracia, cómo afecta a sus costumbres, a sus modos y formas de vida, qué efectos tiene, en definitiva, sobre la moral de un pueblo una organización política basada en la toma de decisiones colectivas, el sorteo o la participación directa en los asuntos públicos? La confianza en las instituciones hace que los atenienses redoblen la confianza en sí mismos:

El demócrata que estipula junto a otros como él el destino de su sociedad no necesita de un Estado que le diga cómo sentir ni cuándo actuar; él ya transformó dicho destino en una segunda piel y por 
tanto su naturaleza, por sí sola, se dispara como un resorte cuando una amenaza ensombrece el horizonte (Hermosa, 2019, p. 88).

Esa confianza, unida a labúsqueda de la felicidad, la racionalidad, la moderación, la responsabilidad cívica o la inclinación indistinguible a la belleza y el bien, es decir, a la kalokagathía o lo bellibueno, como le gusta decir a Emilio Lledó, son algunos de los valores que atesora el ciudadano que actúa dentro del perímetro democrático. ¿Qué sucede cuando un imprevisto, en este caso una enfermedad funesta, la peste, cáncer de las sociedades arcaicas, asola la ciudad? Antonio Hermosa resalta que la línea de demarcación entre civilización y barbarie es tan delgada que cualquier contratiempo puede echar por tierra los logros políticos conseguidos y provocar una regresión colectiva a un estadio precivilizatorio y brutal.

De este modo, en el capítulo $\mathrm{V}$, "¿Conversando atenienses y melios? La paz imposible entre el poder y la justicia en el orden internacional", se evidencia la deriva de la democracia ateniense al centrar el profesor Hermosa el foco de sus pesquisas en los hechos de Melos. Y recuérdese en este punto que la isla, una colonia espartana proclive a sus fundadores, decide mantenerse neutral en el conflicto que enfrenta a Esparta con el Ática, pero, y esto es lo decisivo, los atenienses niegan la opción a los melios de quedarse al margen, forzándolos ora a concertar una alianza con ellos, ora a asumir las consecuencias de su negativa, es decir, aceptar su propia destrucción.

La recensión del relato de Tucídides es memorable: el Poder no negocia. "Los atenienses hacen ver que la agenda está marcada, que lo que está en juego es la opción entre su vida y la libertad y no entre la alianza o la neutralidad" (Hermosa, 2019, p. 123). Los melios se ven, no solo privados de la libertad, el derecho o la justicia, sino que se les condena, en primer lugar, a la incertidumbre porque ningún valor puede concitar respeto ni unanimidad si no se funda en la fuerza; y, en segundo lugar, a la muerte: su masacre es el corolario funesto de una democracia en retirada.

Esto mismo y no otra cosa, por cierto, es lo que la violenta guerra de Corcira muestra sin ambages, a saber, que el despliegue de las pulsiones irracionales más violentas obnubilan a quienes antes eran guiados por una especie de vigor saludable del espíritu, caracterizado por la prudencia, el respeto a las leyes y la sumisión 
al destino. Ahora no es la impunidad frente al castigo ni el respeto a las normas lo que vertebra la vida de los hombres: la muerte en cadena desata una violencia descarnada, pero la novedad radica en el método empleado en la producción del mal. ¿Qué sucede cuando la barbarie se apodera de las relaciones humanas? ¿Cómo afecta a las relaciones humanas la transvaloración de los términos y la alteración semántica de los significados? ¿Qué consecuencias políticas se siguen de la aniquilación del valor de la palabra? La respuesta a la pregunta ¿Por qué se inflige el mal? "Porque se quiere" (Hermosa, 2019, p. 152)-, aterradora en su sencillez, advierte que las pulsiones agresivas del sapiens pueden desatarse en cualquier momento y provocar las atrocidades más funestas, reinstaurar la arbitrariedad y la venganza y, por tanto, eliminar de la vida pública cualquier atisbo de justicia.

El hombre tras los hechos repasa en su recta final el abismo al que se enfrenta la República romana, primero mediante la descripción que hace Salustio de la degeneración tanto de las élites aristocráticas representadas en la figura de Catilina como de la plebe, pero sobre todo de la aristocracia, que no duda "en servirse de la violencia a fin de sacrificar la república a sus intereses" (Hermosa, 2019, p. 157). Después, Tito Livio "recupera la dignidad de la acción política al reconocer como su fundamento básico el derecho y al rechazar el móvil de la venganza como criterio de sus relaciones con los enemigos" (2019, p. 201). Con ello no se garantiza el acatamiento de la legalidad, pero al menos se libera a la política de su sujeción a una voluntad caprichosa orientada al servicio de un interés ajeno. Por fin, se repasa en primer lugar el incendio del Capitolio y la destrucción de Cremona narrada en sus Historias por Tácito, con el objetivo de patentizar la función corrosiva de la codicia sobre una comunidad política cualquiera -auri sacra fames-; en segundo lugar, Antonio Hermosa trae a colación el amotinamiento de las legiones romanas en Panonia y Germania porque en esa "fétida atmósfera de degradación moral” (p. 222) Roma empieza irremisiblemente a tambalearse sobre los cimientos de las nefandas y nihilizantes guerras civiles.

Las cuestiones que el ensayo de Antonio Hermosa deja abiertas como una herida imposible de suturar, cuestiones que son tan antropológicas como ontológicas y, por tanto, eminentemente políticas, invitan a repensar los problemas actuales que deben 
resolverse colectivamente y que amenazan, además, con paralizar a cualquier sociedad. En todo caso, y dándole la vuelta a la fórmula de Esquilo, de este ensayo bien podría afirmarse que su lectura lleva a un ton chaírei máthos, es decir, no a aprender sufriendo, sino, al contrario, a hacerlo gozando 